\title{
Nasal Cavity Actinomycosis Mimicking Nasal Cavity Tumor: A Case Report
}

\section{Hamida Ardhaoui*, Sana Mallouk, Youssef Oukessou, Sami Rouadi, Reda Abada, Mohamed Mahtar and Mohamed Roubal}

Department of Otorhinolaryngology, Head and Neck Surgery, King Hassan II University Hospital, Morocco

Submission: May 07, 2020; Published: June 04, 2020

*Corresponding author: Hamida Ardhaoui, Department of Otorhinolaryngology, Head and Neck Surgery, King Hassan II University Hospital, Casablanca, Morocco

\section{Abstract}

Actinomycosis is a chronic bacterial infection with granulomatous and suppurative features, caused by gram-positive anaerobic: actinomycetes. Generally, saprophytes of the natural cavities of man, but which can become pathogenic under certain conditions. This pathology is most common in the cervicofacial region. Involvement of the paranasal sinuses is extremely rare which can take on the appearance of tumor affections. We describe a case of nasal cavity actinomycosis diagnosed in 16-year female consulted for a left nasal airway obstruction associated with purulent rhinorrhea.

Keywords: Actinomycosis; Granulomatous; Saprophytes; Maxillofacial trauma; Posterior rhinos; Nasal cavity; Cavum; Soft palate; Mycotic disease; Germs; Paranasal sinus; Allergy; Clindamycine; Tetracycline; Penicillin therapy

\section{Introduction}

Actinomycosis is a rare suppurative granulomatous infection, characterized by the formation of multiple abscesses, often chronic. The responsible germ is Gram-positive, filamentous anaerobic or facultative anaerobic: actinomycetes. Generally, saprophytes of the natural cavities of man, but which can become pathogenic under certain conditions. Actinomyces israelii is most often involved in human pathology. This pathology is most common in the cervicofacial region [1]. Involvement of the paranasal sinuses is extremely rare.

\section{Observation}

A 16-years-old female, who consulted for a left nasal airway obstruction associated with purulent rhinorrhea and epistaxis evolving for 3 months. The patient has no particular medical history and no notion of maxillofacial trauma. Physical examination demonstrated a red left eye with onset of exophthalmos without reduced visual acuity. At the anterior and posterior rhinos copy, we noted the presence of a whitish mass which leaves the left middle meatus and which reaches the floor with invasion of the soft palate. We also noted the presence of purulent secretions at the level of the left nasal cavity with a congestive mucosa. The cavum and the cervical lymph nodes are clear. Examination of the oral cavity finds a small perforation of the soft palate with the result of whitish secretions (Figure 1).

The facial scanner demonstrated a locally advanced posterolateral tumor process of the cavum, measuring approximately: $52.5 \mathrm{~mm} \times 28.7 \mathrm{~mm} \times 24.5 \mathrm{~mm}$. Which is enhanced after injection of PDC with pan sinusitis (Figure 2). A biopsy was performed which showed the presence of necrotic and inflammatory material showing tumor-like necrosis. Given the CT aspect and the anatomopathologycal results, a tumor lesion is suspected. Surgical excision is then indicated for diagnostic and therapeutic purposes. The patient underwent endoscopic surgery. Surgical exploration found a friable, granular tissue, without any real tumor mass (Figure 3). The extemporaneous histological examination revealed necrotic and fibrinocytic material containing actinomycotic bodies evoking an actinomycosis with absence of neoplastic process. The patient was prescribed two weeks of intravenous penicillin G (5million U/day) followed by six months of amoxicillin-clavulanate. The evolution was favorable, with no recurrence with a 3 years decline. 


\section{Global Journal of Otolaryngology}

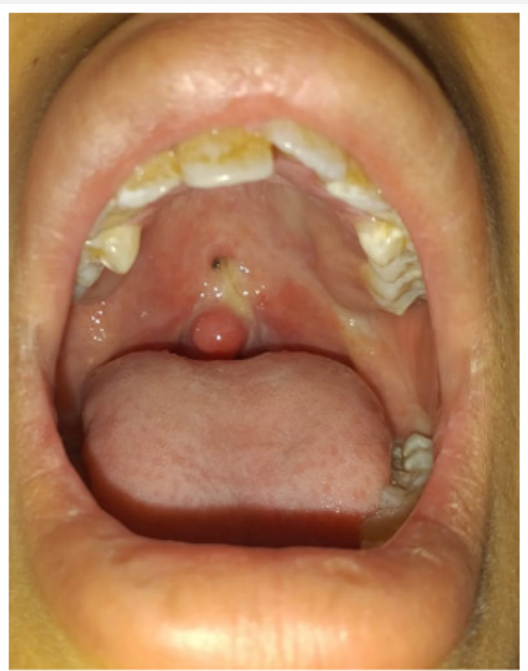

Figure 1: Examination of the oral cavity finds a small perforation of the soft palate with the result of whitish secretions.

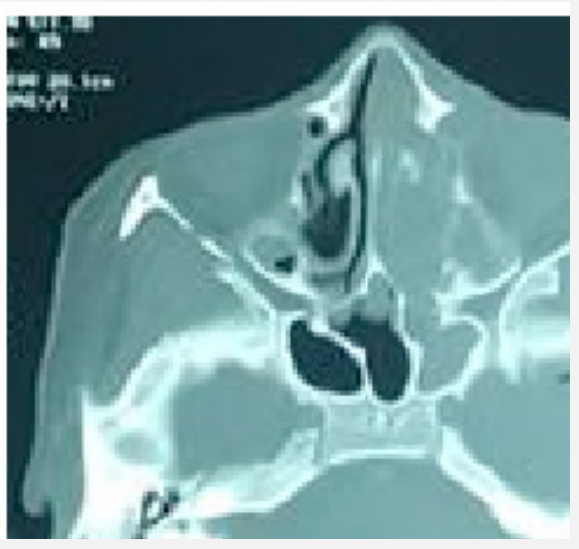

Figure 2: The facial scanner demonstrated a locally advanced posterolateral tumor process of the cavum, measuring approximately: $52.5 \mathrm{~mm} \times 28.7 \mathrm{~mm} \times 24.5 \mathrm{~mm}$ with pan sinusitis

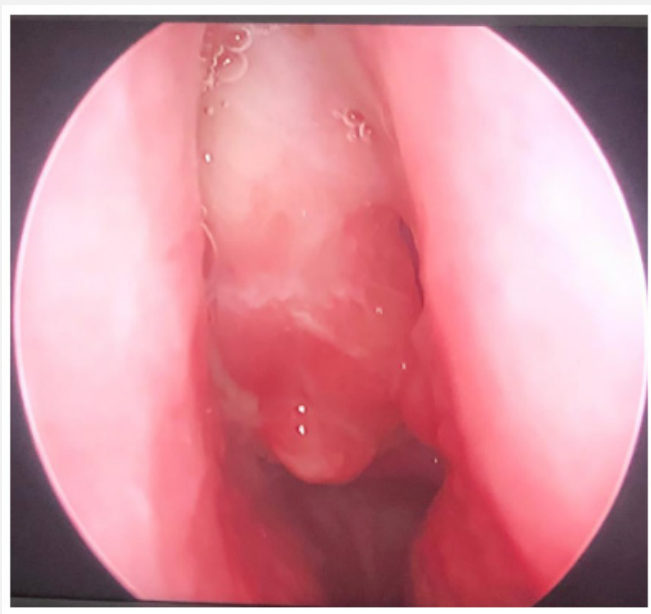

Figure 3: Surgical exploration found a friable, granular tissue, without any real tumor mass. 


\section{Discussion}

Actinomycosis was first described in the early 19th century as a disease of cattle. However, the publication of the first description of actinomycosis in humans was in 1857 by LEBERT [2]. Actinomycosis is a term Greek: actino in relation to sulfur granules and mycos means a mycotic disease [2,3]. This infection was considered to be rare (reported annual incidence of $1 / 300000$ persons), can be explained by the difficulty of diagnosis and the frequent association with other germs [4]. The predominance of the disease in rural areas is classic due to poor hygiene. It is generally occurs in adults (20 to 60 years), with a male predominance (male-to-female ratio: $3: 1$ ) [4,5].

Actinomycosis is a chronic bacterial infection with granulomatous and suppurative features, caused by gram-positive anaerobic, non-acid-fast bacteria, non-spore-forming, that is a saprophytic germ in human flora of the female genitourinary and gastrointestinal tracts, they are never found in the free state in nature. Actinomyces israelii is most often involved in human pathology [6,7]. Actinomyces are spontaneously not very pathogenic, two main predisposing factors for the occurrence of actinomycotic infection are: the existence of a pathway into the tissue and an anaerobic environment conducive to the multiplication of microorganisms $[4,6]$. It can affect all organs with a predominance of the cervicofacial region (cervicofacial region $40-60 \%$, abdominal region $20-30 \%$, thoracic region 20 $25 \%$ and pelvic region $3-5 \%$ ] $[1,4,5,7,8]$.

Paranasal sinus actinomycosis is rare, it manifests clinically as a chronic unilateral rhinosinusitis, which does not respond to medical therapy, with rhinorrhea, nasal airway obstruction and congestion, similar to the presented case [9]. Medical interventions as cervicofacial surgery and dental extractions, poor dental hygiene, trauma and immunocompromised status represent the main risk factors $[7,4,5]$. The diagnosis is difficult due on the one hand to the polymorphic clinical aspect of the disease and on the other hand to the difficulty in highlighting the germ in culture. Often, it is the histopathological examination, which confirms the diagnosis of actinomycosis by visualization of typical sulfur granules [10]. Radiologic findings are not specific but CT scans can determine exact location of the lesion and extent of involvement.

The treatment of actinomycosis is based on antibiotic therapy alone or in some cases combined with surgery. The antibiotic of choice is penicillin but in case of allergy, clindamycine and tetracycline can be used [11]. Nevertheless, there is no consensus either on the duration or on the dosage. In older series, the recommended treatment is high dose penicillin therapy (5 to 20 million $\mathrm{U} /$ day relayed by penicillin $\mathrm{V}$ at the dose of 2 to 5 million U/day.) for a long period (6 months to 1 year) [5,7]. However, several authors have reported the efficacy of short-term antibiotic therapy, particularly in cervicofacial locations $[12,13]$. Surgery may be for therapeutic purposes, or for diagnostic and therapeutic purposes. For our patient, the diagnosis of certainty was made postoperatively. Endoscopic surgical will allow abscess drainage and removal of the tissues involved thus avoiding recurrences and restoration of sinus ventilation [1]. The prognosis of the disease depends on early diagnosis and treatment, as it is a curable disease if properly diagnosed and treated.

\section{Conclusion}

Paranasal sinus actinomycosis is rare. However, it should be considered in the differential diagnosis of chronic unilateral sinusitis does not respond to medical therapy. The treatment of actinomycosis includes endoscopic surgery and antibiotic therapy. The prognosis of the disease depends on early and adequate diagnostic and therapeutic care.

\section{References}

1. Oostman O, Smego R A (2005) Cervicofacial Actinomycosis: Diagnosis and Management. Curr Infect Dis Rep 7: 170-174.

2. Max miller, Albert Jason Haddad (1998) Cervicofacial actinomycosis. Oral Surg Oral Med Oral Patol Oral Radiol Endod 85: 496-508.

3. L Aderdour, K Koulali, L Bassi, A Raji, B Theolyere, et al. (2010) Ostéite mandibulaire d'origine actinomycosique. La lettre de l'infectiologue. Tome XXV-n ${ }^{\circ} 1$ - janvier- février.

4. Boyanova L, Kolarov R, Mateva L, Markovska R, Mitov I (2015) Actinomycosis: A frequently forgotten disease. Future Microbiol 10: 613-628.

5. F Vaulor, A Sénéchal, C Dupieux, J Karsenty, S Lustig, et al. (2014) Actinomycosis: etiologiy, clinical features, diagnosis, treatment, and management. Infect Drug Res 7: 183-197.

6. Gajdacs M, Urban E, Terhes G (2019) Microbiological and Clinical Aspects of Cervicofacial Actinomycosices Infections: An Overview. Dentistry journal Sep 7(3): 85.

7. Kononen E, Wade WG (2015) Actinomyces and related organisms in human infections. Clin Microbiol Rev 28: 419-442.

8. Marret H, Wagner N, Ouldamer L, Jacquet A, Body G (2010) Pelvic actinomycosis: just think of it. Gynecol Obstet Fertil. 38(5): 312.

9. M Roth, KT Montone (1996) Actinomycosis of the paranasal sinuses: a case report and review, Otolaryngology- Head and Neak Surgery 114(6): 818-821.

10. Nagy E, Boyanova L, Justesen US (2018) How to isolate, identify and determine antimicrobial susceptibility of anaerobic bacteria in routine laboratories. Clin Microbiol Infect 24: 1139-1148.

11. N Vorasubin, AW Wu, C Day, JD Suh (2013) Invasive sinonasal actinomycosis: case report and literature review, Laryngoscope 123(2): 334-338.

12. Shah KM, Karagir A, Kanitkar S, Koppikar R (2013) An Atypical form of cervicofacial actinomycosis treated with short but intensive antibiotic regimen. BMJ Case Rep bcr2013008733.

13. Sudhakar SS, Ross JJ (2004) Short-term treatment of actinomycosis: two cases and review. Clin Infect Dis 38: 444-447. 
(C) This work is licensed under Creative (C) DOI: 10.19080/GJO.2020.22.556090
Your next submission with Juniper Publishers will reach you the below assets

- Quality Editorial service

- Swift Peer Review

- Reprints availability

- E-prints Service

- Manuscript Podcast for convenient understanding

- Global attainment for your research

- Manuscript accessibility in different formats

( Pdf, E-pub, Full Text, Audio)

- Unceasing customer service

Track the below URL for one-step submission https://juniperpublishers.com/online-submission.php 